\title{
The impact of new guidelines for glucose tolerance testing on clinical practice and laboratory services
}

\author{
Andrew W. Lyon, Erik T. Larsen, Alun L. Edwards
}

T The Canadian Diabetes Association's 2003 clinical practice guidelines for diabetes mellitus were published in mid-December 2003. ${ }^{1}$ These guidelines retain the fasting plasma glucose test for the diagnosis of diabetes, and the criterion for diagnosis (fasting plasma glucose level of $7.0 \mathrm{mmol} / \mathrm{L}$ or more) remains unchanged. However, the guidelines now include a new recommendation: that anyone with a risk factor for diabetes and a fasting plasma glucose level between 5.7 and $6.9 \mathrm{mmol} / \mathrm{L}$ should be considered for an oral glucose tolerance test (OGTT). ${ }^{1}$ The previous version of the guidelines, ${ }^{2}$ published in 1998, lacked management guidelines for the diagnostic category of impaired fasting glucose (fasting plasma glucose level of 6.1 to $6.9 \mathrm{mmol} / \mathrm{L}$ ). The move to recommend more OGTTs responds to consistent reporting of a significant number of people with fasting plasma glucose values below the diagnostic threshold for diabetes but with postload glucose values exceeding the diagnostic cut-off of $11.1 \mathrm{mmol} / \mathrm{L}$. If the new recommendation is followed, the prevalence of diagnosed diabetes should increase, and the significant number of undiagnosed cases should be correspondingly reduced., ${ }^{3,4}$

There is a presumption that diagnosis earlier in the natural history of the disease would be beneficial for longterm outcome, but the new recommendation is still based on relatively weak evidence (grade $\mathrm{D}$, consensus). ${ }^{1} \mathrm{Al}$ though there may be some benefit to earlier diagnosis, this new recommendation will influence both clinical practice and laboratory services and has the potential to ignite a new round of debate among Canadian physicians on the merits of improving the recognition and diagnosis of diabetes. ${ }^{5-7}$

Strong evidence exists that interventions can reduce the progression of impaired glucose tolerance to diabetes mellitus over time, ${ }^{8,9}$ and this evidence has also driven the recommendation to promote formal glucose tolerance testing over a wider range of fasting plasma glucose levels than impaired fasting glucose alone. ${ }^{1}$ It should be recognized, however, that the cited intervention trials examined people with impaired glucose tolerance precisely because this group is known to have a high event rate. Impaired glucose tolerance is a phase in the natural history between "at risk" and the development of diabetes. It is reasonable to assume that "at-risk" patients with normal glucose tolerance or im- paired fasting glucose would benefit from lifestyle interventions, and the need for definitive determination of impaired glucose tolerance is moot.

The recommendation to use a 2-hour OGTT for patients with fasting plasma glucose levels between 5.7 and $6.9 \mathrm{mmol} / \mathrm{L}$ restores an imprecise and labour-intensive tool to avoid underdiagnosis of diabetes and impaired glucose tolerance. ${ }^{10,11}$ The OGTT may be familiar to physicians, and it is a more sensitive test for diabetes than the fasting plasma glucose test in older and less obese patients; $;^{1,13}$ however, it has poor reproducibility (results are reproducible for less than $60 \%$ of patients ${ }^{1,15}$ ). Recent reports have argued that testing of hemoglobin $A_{1 C}$ levels could be used diagnostically with greater precision, sensitivity and convenience to patients, ${ }^{16}$ although the evidence required for a clinical practice guideline recommendation is still lacking. ${ }^{1}$

Complete adherence to the new guidelines would have a large impact on laboratory services that, in the absence of additional financial resources, could be detrimental to health service delivery. We gathered data on fasting plasma glucose tests for different patients (repeat tests excluded) from the main laboratory service provider in the Calgary region (Calgary Laboratory Services) for the period Sept. 1 to Nov. 30, 2003. The distribution of the 57357 fasting plasma glucose values obtained in the Calgary Health Region for this 3-month period shows that for $8469(14.8 \%)$ of all patients tested the glucose level was between 5.7 and $6.9 \mathrm{mmol} / \mathrm{L}$ (Fig. 1). The large percentage of test results within this range is anticipated from, and is in accordance with, the reference range for fasting plasma glucose $(14.9 \%$ of the reference distribution lies in this range; Fig. 1). Some of the fasting plasma glucose tests in Calgary may have been performed in people with established diabetes (i.e., not for diagnostic purposes), but we believe that such testing is performed relatively infrequently, unless the patient's lipid profile is also being checked.

If all of the fasting plasma glucose tests were intended for diagnosis and all patients had fasting plasma glucose checked because they were at risk of diabetes, we could anticipate an additional 2823 OGTTs per month (i.e., 8469/3), 19 times the current volume of 150 tests per month (which excludes testing in pregnant women). Age of 
40 years or more is a risk factor, and we found that $94.7 \%$ of the 8469 subjects with fasting plasma glucose values of 5.7 to $6.9 \mathrm{mmol} / \mathrm{L}$ would be considered for an OGTT on the basis of age alone. If we make a very conservative estimate that half of these patients ( 4234 over 3 months or 1411 per month) had unknown diabetic status and another risk factor for the condition, there would still be a substantial increase in the demand for the OGTT.

The OGTT is cumbersome and time-consuming for both the patient and the laboratory service. The procedure includes pretest instructions to patients by telephone when they reserve a testing time, additional instructions given with the glucose drink as the test is initiated and a phlebotomy 2 hours after the drink (estimated total time 25 minutes of labour per patient and approximately 2.5 hours of time when the patient is hosted in the waiting room of the clinic). At this time, with existing resources, it is unlikely that the laboratory service in Calgary has sufficient capacity to accommodate an additional 1400 to $2800 \mathrm{pa}-$ tients per month for this type of testing, a situation that we believe would be reflected nationally.

Integration of these new guidelines into practice may already be under way, and clinical laboratories across Canada will require more resources to support even partial implementation of the guideline. ${ }^{18}$ Does the OGTT really provide sufficient clinical value for these resources? In its recommendations, the Canadian Diabetes Association $^{1}$ recognizes that no single laboratory test has been shown to be adequate for routine diagnostic use; in our view the OGTT in particular is poorly reproducible and cumbersome and its cost-effectiveness questionable. Further research might allow the development of tools for stratifying the risk of diabetes according to several variables (e.g., age, family history, waist measurement, hemoglobin $\mathrm{A}_{1 \mathrm{c}}$ level, fasting plasma glucose level), just as other scoring systems are used to determine cardiovascular risk. ${ }^{1,19,20}$ Such scoring of risk factors might help to guide interventions that have already been proven to prevent diabetes. ${ }^{21-23}$ However, in the absence of an established tool to diagnose early diabetes, clinicians could identify known risk factors in their patients (e.g., obesity, sedentary lifestyle, family history of diabetes) and could empirically counsel patients regarding lifestyle changes to modify these risk factors. Such measures can be undertaken even in the absence of biochemical markers of dysglycemia. We believe that devoting resources to programs that can help patients to modify their risks for diabetes is preferable to performing more OGTTs of dubious specificity, according to a recommendation that is based on inadequate evidence and consensus opinion.

From the Department of Pathology and Laboratory Medicine (Lyon, Larsen) and the Department of Medicine (Edwards), University of Calgary, Calgary, Alta.; and Calgary Laboratory Services, Calgary, Alta. (Lyon, Larsen)

Competing interests: None declared.

Contributors: All 3 authors developed the design of the project from an original concept of Alun Edwards. Andrew Lyon and Erik Larsen directed the data acquisition and analysis. All authors participated in interpreting the data and writing the article, and all have given their final approval of the submitted version.

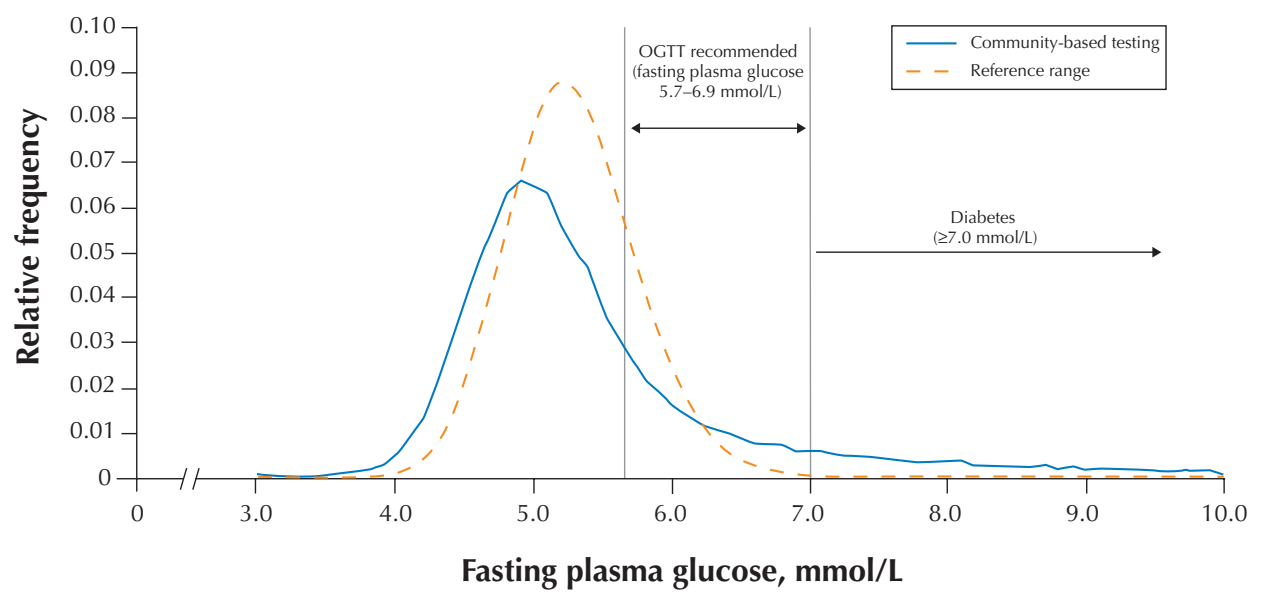

Fig. 1: Frequency distribution of fasting plasma glucose values in the Calgary Health Region. The solid line represents the results of community-based testing for any reason from Sept. 1 to Nov. 30, 2003 (57 357 tests; repeat test results per patient omitted). The broken line represents the frequency distribution of a reference range for fasting plasma glucose (derived by reverse natural logarithm transformation of a distribution with the World Health Organization 97.5\% upper limit of 6.1 $\mathrm{mmol} / \mathrm{L}$ and a recent estimate of the standard deviation of this distribution in a Scandinavian reference population ${ }^{17}$ ). For both curves, relative frequency is plotted for intervals of $0.1 \mathrm{mmol} / \mathrm{L}$ glucose. OGTT $=$ oral glucose tolerance test 


\section{References}

1. Canadian Diabetes Association 2003 clinical practice guidelines for the prevention and management of diabetes in Canada. Can f Diabetes 2003;27(Suppl 2):S10-3.

2. Meltzer S, Leiter L, Daneman D, Gerstein HC, Lau D, Ludwig S, et al. 1998 clinical practice guidelines for the management of diabetes in Canada. CMAF 1998;159(8 Suppl):S1-29.

3. Diabetes in Canada. 2nd ed. Ottawa: Health Canada; updated 2003 Jan 17. Available: www.hc-sc.gc.ca/pphb-dgspsp/publicat/dic-dac2/english/01 cover_e .html (accessed 2004 Sep 16).

4. Kernohan AFB, Perry CG, Small M. Clinical impact of the new criteria for the diagnosis of diabetes mellitus. Clin Chem Lab Med 2003;41:1239-45.

5. Marshall KG. The folly of population screening for type 2 diabetes [editorial]. CMA7 1999;160(11):1592-3

6. Gerstein HC, Meltzer S. Preventive medicine in people at high risk for chronic disease: the value of identifying and treating diabetes [editorial] CMA7 1999;160(11):1593-4, discussion 1595-6.

7. Young TK, Mustard CA. Undiagnosed diabetes? Does it matter? CMAf $2001 ; 164(1): 24-8$

8. Tuomilehto J, Lindstrom J, Eriksson JG, Valle TT, Hamalainen H, IlanneParikka $\mathrm{P}$, et al. Prevention of type 2 diabetes mellitus by changes in lifestyle amongst individuals with impaired glucose tolerance. N Engl 7 Med 2001;344 (18): $1343-50$.

9. Knowler WC, Barrett-Connor E, Fowler SE, Hamman RF, Lachin JM, Walker EA, et al; Diabetes Prevention Program Research Group. Reduction in the incidence of type 2 diabetes with lifestyle intervention or metformin. $N$ Engl7 Med 2002;346(6):393-403.

10. Ganda OP, Day JL, Soeldner JS, Connon JJ, Gleason RE. Reproducibility and comparative analysis of repeated intravenous and oral glucose tolerance tests. Diabetes $1978 ; 27: 715-25$.

11. Ko GT, Chan JC, Woo J, Lau E, Yeung VT, Chow CC, et al. The reproducibility and usefulness of the oral glucose tolerance test in screening for diabetes and other cardiovascular risk factors. Ann Clin Biochem 1998;35:62-7.

12. Shaw JE, de Courten M, Boyko EJ, Zimmet PZ. Impact of new diagnostic criteria for diabetes on different populations. Diabetes Care 1999;22:762-6.

13. Will new diagnostic criteria for diabetes mellitus change phenotype of patients with diabetes? Reanalysis of European epidemiological data. DECODE Study Group on behalf of the European Diabetes Epidemiology Study Group. BM7 1998;317(7155):371-5.
14. Sievenpiper JL, Leiter LA, Vuksan V. Intrasubject coefficient-of-variation corresponds to diagnostic reproducibility in diabetes screening. Can 7 Diabetes $2002 ; 26: 105-12$.

15. Schousboe K, Henriksen JE, Kyvik KO, Sorensen TI, Hyltoft Petersen P. Reproducibility of S-insulin and B-glucose responses in two identical oral glucose tolerance tests. Scand 7 Clin Lab Invest 2002;62(8):623-30.

16. Anand SS, Razak F, Vuksan V, Gerstein HC, Malmberg K, Yi Q, et al. Diagnostic strategies to detect glucose intolerance in a multiethnic population. $\mathrm{Di}$ abetes Care 2003;26:290-6.

17. Jorgensen LG, Stahl M, Brandslund I, Hyltoft Petersen P, Borch-Johnsen K, de Fine Olivarius N. Plasma glucose reference interval in a low-risk population. 2. Impact of the new $\mathrm{WHO}$ and ADA recommendations on the diagnosis of diabetes mellitus. Scand 7 Clin Lab Invest 2001;61(3):181-90.

18. Van Walraven C. Practice guidelines and practicing physicians - Who's guiding whom? [editorial]. Clin Chem 2002;48:9-10.

19. Genest J, Frolich J, Fodor J, McPherson R (the Working Group on Hypercholesterolemia and Other Dyslipidemias). Recommendations for the management of dyslipidemia and the prevention of cardiovascular disease: 2003 update. CMA7 2003;168(9):Online-1 to Online-10. Available: www.cmaj.ca/cgi/ content/full/169/9/921/DC1 (accessed 2004 Sep 16).

20. Stevens RJ, Kothari V, Adler AI, Stratton IM; United Kingdom Prospective Diabetes Study (UKPDS) Group. The UKPDS risk engine: a model for the risk of coronary heart disease in type II diabetes (UKPDS 56) [published erratum appears in Clin Sci (Lond) 2002;102(6):679]. Clin Sci (Lond) 2001;101(6): $671-9$

21. Stern MP, Williams K, Haffner SM. Identification of persons at high risk for type 2 diabetes mellitus: Do we need the oral glucose tolerance test? Ann Intern Med 2002;136:575-81.

22. Engelau MM, Narayan KMV, Vinicor F. Identifying the target population for primary prevention: the trade-offs. Diabetes Care 2002;25:2098-9.

23. Saydah SH, Byrd-Holt D, Harris MI. Projected impact of implementing the results of the diabetes prevention program in the US population. Diabetes Care 2002;25:1940-5

Correspondence to: Dr. Alun L. Edwards, Diabetes Education Centre, Colonel Belcher Hospital, 1213 4th St. SW, Calgary AB T2R 0X7; fax 403 943-2469; aedwards@ucalgary.ca

\section{Canada's programs to prevent mental health problems in children: the research-practice gap}

\section{John D. McLennan, Harriet L. MacMillan, Ellen Jamieson}

T

he increased number of prevention activities directed at reducing child mental health problems in Canada is welcome. However, practitioners and policy-makers should reflect on 2 questions that were posed 20 years ago by Michael Rutter: "How much do we really know about prevention in the field of psychosocial disorders of childhood?" and "Is it necessarily the helpful enterprise that it is usually portrayed to be?"1

In this commentary we highlight examples of the mismatch between what is known and what is practised in the prevention of child mental health problems in Canada, identify some of the underlying factors that may contribute to the gap between research and practice, and make recommendations for strengthening the link between research and practice.

A number of preventive interventions have been shown in replicated randomized controlled trials (RCTs) to be ef- fective in reducing child psychosocial problems. We briefly outline 3 exemplary prevention programs in the US and contrast these with a set of programs used in Canada.

The Nurse-Family Partnership. This is one of the most rigorously evaluated early-years interventions. It is an intensive US program of pre- and postnatal home visits by nurses to at-risk, first-time mothers. In 3 different RCTs the program has demonstrated multiple positive maternal and child outcomes in the short and long term. These include reductions in child abuse and neglect, in antisocial behaviour in youth and in behavioural problems related to the use of drugs and alcohol among adolescents. ${ }^{2-4}$ An equivalent program has not been implemented in Canada. A number of Canadian programs use the Healthy Families America model, in which home visitation is provided by trained lay staff. The home visitation component of the Healthy Babies, Healthy Children 